\title{
Risk Management in Scrum Projects: A Bibliometric Study
}

\author{
Breno G. Tavares, Carlos Eduardo S. da Silva and Adler D. de Souza
}

\begin{abstract}
This article presents a bibliometric study of Risk Management in Scrum Projects. It was carried out an analysis involving the ISI Web of Knowledge and Scopus databases, identifying the main authors, countries and periodicals. It also identified the most cited authors by the analyzed articles, in addition to the keywords most frequently cited. These analyzes were performed using the reference maps, which were generated by CiteSpace ${ }^{\circledR}$ software, which offers a set of features to support bibliometrics. The objective was to identify the current scenario research of Risk Management applied in Scrum Projects in order to offer a consistent basis of information to researchers. The research verified that, despite the importance of the research topic, few scientific studies have been identified, which brings the need for new researches on the subject.
\end{abstract}

Index Terms - Bibliometric study, ISI Web of knowledge, Risk Management, Scrum, Scopus

\section{INTRODUCTION}

$\mathrm{T}$ HE Scrum framework is the most used agile methodology in software project management [8], [14], [44] and provides a set of best practices aimed to fast delivery of value to the customer. The significant growth in the adoption of these methodologies can be seen through the researches [30], [31], [32], [33]. Specifically about Scrum, [31] observed an increase of 7\% in its adoption between the years 2011 and 2013.

Despite the growth in adoption of project management and in particular the adoption of Scrum, [6] and [45] observed that risk management has been neglected in project management. Other studies have also identified the absence or inadequate application of risk management in software projects [11], Singh Sharma \& Chandra, 2012; Bannerman, 2008) and in projects using the Scrum framework [10], [39].

Risk management is able to reduce uncertainty and increase the possibility of success of the projects [1], [34] [35], [40], however, is treated implicitly in projects using agile methodologies [2], [7], [13], [41]. Considering the importance of the topic presented, this article provides a study of scientific publications on the topic Risk Management in Scrum Projects

Manuscript received July 13, 2016; revised October 28, 2016 and February 28, 2017. Date of publication: March 28, 2017.

Authors are with Universidade Federal de Itajubá, Brazil (E-mails: breno.tavares@inatel.br, \{sanches, adlerdiniz\}@unifei.edu.br).

Digital Object Identifier (DOI): 10.24138/jcomss.v13i1.24 and discusses the key features found in the main items identified by the bibliometric review.The research was conducted using bibliometrics, which allows you to analyze the development of a field of science, to identify its characteristics [5]. This work is divided into five sections. The first section contextualize the theme. The second presents some brief concepts of Scrum and Risk Management. The third presents the research method used in this work. The fourth shows the results obtained from the bibliometry. Finally, the fifth section presents the general conclusions.

\section{THE SCRUM FRAMEWORK}

Scrum is defined by its creators [16] as a structural framework used to manage complex products that allows the integration of various processes or techniques. According to [36], a framework is a structure to support or attach other items, in other words, a skeletal support used as a base for something that is being built.

The rules, team roles, artifacts, events are Scrum components. The rules integrate the other three components, managing the relationships and interactions between them [16]. The roles are divided into Development Team, Product Owner and Scrum Master. Scrum teams are multifunctional, able to complete the work without relying on people outside the team. Furthermore, the Scrum teams are self-organized, enabling the teams to define the best way to do the work without the need to be led by someone from outside the team.

The development team is the group of qualified members, typically from 3 to 9 members, who help in achieving the goals of the project and releasing product at the end of each sprint [4]. The product owner has the responsibility to formulate the plan according to the problem and dividing them among the development team in such a manner to get better functionality and results [50]. The Scrum master plays a vital role as the Scrum master is a person who leads the development team and keeps an eye on them, guide them, help them, resolves issues, make necessary improvements etc.

Scrum prescribes five events, also known as ceremonies, all of them are time-framed and can not be reduced or increased [16]. These events are designed to enable transparency and inspection of projects. If any event is not run, will result in less transparency and loss of opportunity of inspection and project adaptation [16]. Figure 1 represents the Scrum life cycle. 


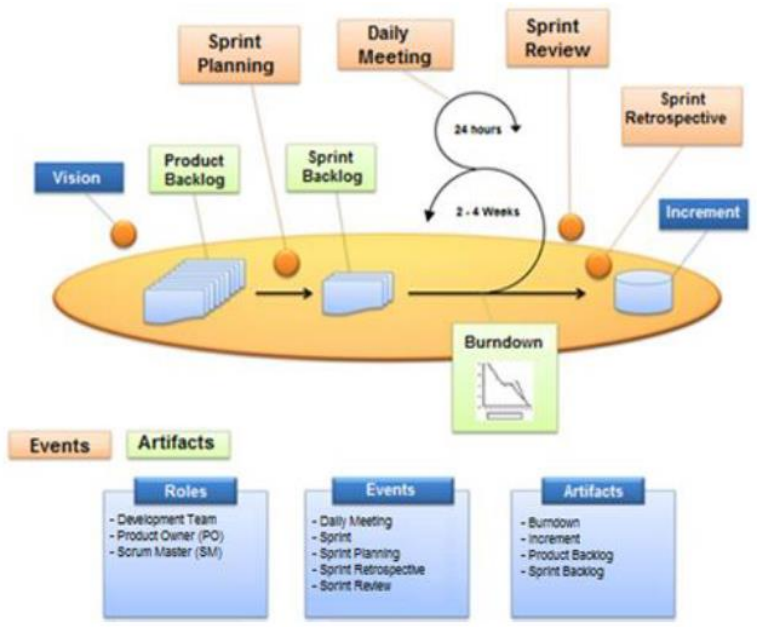

Fig. 1. The Scrum life cycle. Adapted from Ettinger (2016).

Scrum life cycle begins with the vision that Product Owner has regarding the product that he wants to create and on that basis, a prioritized list is made containing product features called Product Backlog. Then a Sprint begins with the Sprint planning and Sprint Backlog which includes the tasks to be done by the team. In Sprint Planning, the team makes the decision of choosing a task from the Product Backlog, which they believe that they can complete it within a Sprint cycle. Then come Sprint Backlog in which task is broken down into units that is carried forward by the team who determines the best way to accomplish the goal within each sprint cycle. Daily Scrum meetings, which typically takes 15 minutes, are also organized so that we get the direction of our project as well as its progress.

At the end of each Sprint cycle, there is Sprint Review in which the product is well inspected by the stakeholders including customers, Scrum team and all associated members. They visualize the product and give feedback. Then comes Sprint Retrospective, which is followed by the Sprint Review. Sprint Retrospective is done before next sprint planning in which the Scrum team is involved that focus on further improvements in order to get better results in the next Sprint phase [15] [48].

The artifacts are another kind of Scrum component that are designed to maximize the information transparency. Among the artifacts, the Product Backlog stands out, which is an ordered list of all the items that are needed in the product. The Sprint Backlog is a list of Product Backlog items that should be developed at Sprint. At the end of the Sprint another artifact is created. This is the increment that is the sum of the Sprint Backlog items. The increment must be "Ready", therefore, must be in usable condition and meet the definition of "Ready" created by the Scrum team.

\section{RISK MANAGEMENT IN SCRUM PROJECTS}

Project risks is defined as a set of factors or conditions that may pose a threat to project success [47]. It is important to quantify a risk, evaluate the probability of its occurrence, and its potential impact on the project [49]. According to [16], the Scrum framework uses an iterative and incremental approach to optimize predictability and risk control. The authors state that the use of Sprints also supports risk management, as it limits risk to one calendar month of cost [16].

However, for [7] and [13], none of agile methodologies explicitly suggests steps or processes for risk management and its management can being negligencead. According to [46], Risk management in Scrum is not as good as in traditional management practices, because some specific risk management practices are not meet, except the risk identification activity.

Scrum lifecycle allows product tracking and the identification of impediments. Some authors define the impediment as a project risk [37], [38], while others state that there are differences between these two concepts [39], [42], [43].

According [38] and [42], impediment is defined as any occurrence that prevents any member of Scrum team to develop their work efficiently. This research uses the definition of impediment proposed by [43], as a problem that has already occurred and that is affecting the project's progress, making thus distinction between risk and impediment definitions.

In this context, risk management when used in Scrum projects enables prevent the occurrence of impediments, implementing proactive measures to inhibit that project risks become impediments in the future [43].

For [51], the impediment management reduces the project overall risk, since the impediments are problems that can bring risks to the schedule, budget, among others. The Impediment Impact Diagrams is a technique presented by [52], which removes impediments from agile teams and organizations. Thus, we believe that techniques for dealing with impediments help in risk management in Scrum projects.

\section{RESEARCH METHOD}

The bibliometric analysis is a quantitative analysis tool introduced as an analysis technique by Pritchard in the late 60 [12], and is an area of study in information science, which has key role in scientific production analysis [22], [25].

The bibliometrics is intended to measure, through statistical analysis, the scientific research production in the form of articles, publications, citations, patents, among other indicators, enabling the evaluation of research, scientists, institutions, countries, etc. [29]. The central point of bibliometrics is the use of quantitative methods, seeking to make an objective evaluation of scientific literature [3], through bibliometric indicators [17].

The bibliometric analysis provides knowledge about the history and current state of the research field and provides resources that allow enrich the discussion about the possible directions that research has taken and scientific trends for researchers and interested in the subject [5].

\section{DATA Collection}

For the bibliometric analysis conduction, the search for articles in the chosen databases was held on 26/02/2017 and included only papers published from 2007 to 2017. Another selection criterion was to consider only articles with certain keywords in the topic. Three searches were performed on each 
of the databases, according to the following keywords:

- Scrum Project;

- Risk Management;

- Scrum Project Risk Management.

The development of this study was performed in two stages:

1. Data collection: collected the related data from the ISI Web of Knowledge and Scopus databases for carrying out the bibliometric study.

2. Bibliometric analysis: analysis of the data collected from the use of resources provided by the databases and also by the use of the CiteSpace ${ }^{\circledR}$ software to support bibliometrics.

According to [20], ISI Web of Knowledge database is a good tool for the diagnosis of scientific production, because it is considered the most comprehensive and multidisciplinary basic bibliographic data of scientific information. [24], ISI Web of Knowledge has a small set of scientific journals and defines strict criteria for that magazines are included in the database.

Scopus is a database sponsored by Elsevier, which includes journals and scientific conferences [24]. For [19], Scopus has more indexed journals than ISI Web of Knowledge and offers greater coverage of open access journals.

This research uses the ISI Web of Knowledge and Scopus databases to develop a bibliometric study. For [18], the use of the ISI Web of Knowledge and Scopus databases together in certain subjects is more beneficial than the use of only one, because it improves the identification of relevant citations.

The statistical features and graphics of the ISI Web of Knowledge and Scopus databases were used to support bibliometric analisys, besides the CiteSpace ${ }^{\circledR}$ software which allows you to analyze the connections between authors, institutions, countries, keywords, sources publication or references in scientific literature [4], [27]. According to [21], there are several software tools to support bibliometrics, but CiteSpace ${ }^{\circledR}$ is one of the most powerful. For [27], CiteSpace $\AA$ is the free software that offers more options to perform bibliometric analysis.

\section{RESULTS}

The term "Scrum Project" was used in the first search in the ISI Web of Knowledge and Scopus databases, which obtained 448 and 761 articles, respectively. The number of articles identified in Scopus is greater than the found in ISI Web of Knowledge database.

The term "Risk Management" was also searched in the databases and 194,337 articles were identified at ISI Web of Knowledge and 271,792 at Scopus. It is noted that the number of items identified at Scopus is higher.

From these results, it is observed there is the sheer volume of publications related to the terms: Risk Management and Scrum Project. However, this study aims to carry out the bibliometric study of both terms together, considering only articles of Risk Management in Scrum Projects.

Therefore, a search for these two terms together in these databases was performed. Figure 1 shows the results obtained using the terms, Scrum Project Risk Management. Just as the previous search, this search focused in seeking articles published in the last 10 years and were identified 23 papers at
ISI Web of Knowledge and 42 at Scopus, totaling 65 articles. It is observed that the number of articles is less than the searched terms separately in both databases.

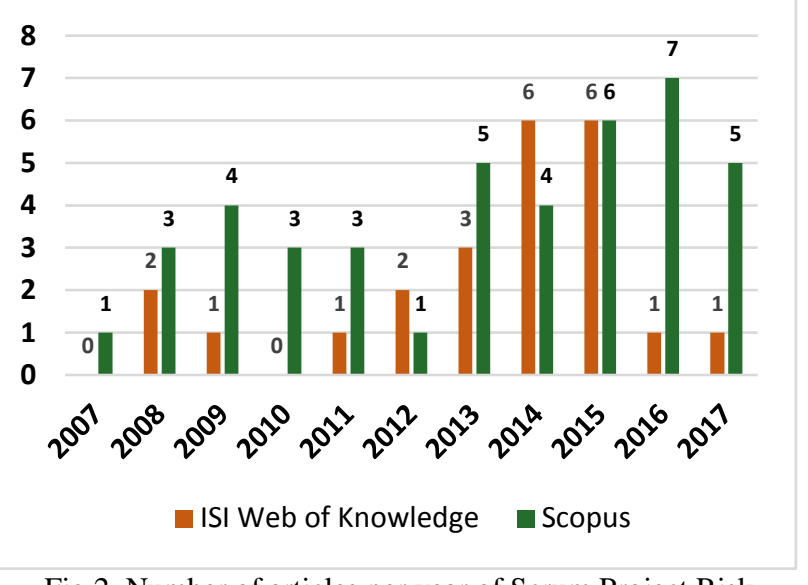

Fig.2. Number of articles per year of Scrum Project Risk Management

Considering the importance of this research field, these 65 articles related to the application of Risk Management in Scrum Projects were used to perform the bibliometric study. The following analysis were made: (i) citation analysis, (ii) identification of the major sources of publication, (iii) identification of the principal authors, (iv) identification of the main countries and $(\mathrm{v})$ construction of the citation map.

Using the citation analysis feature of the databases, it was possible to identify how the articles have being cited over the years. This can be seen in Figure 2. It is observed an increase in the two databases in the last 5 years.

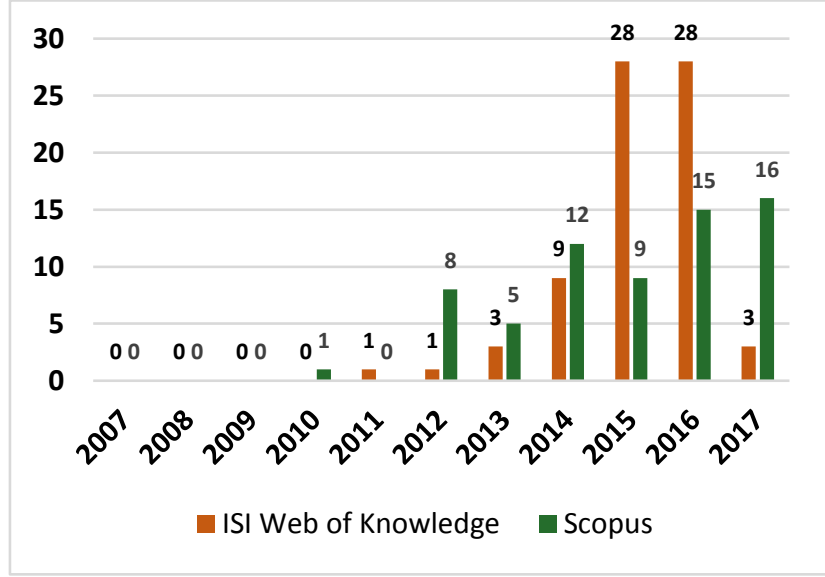

Fig. 3. Number of citations per year

Another feature provided by the ISI Web of Knowledge and Scopus databases is the identification of published sources, for example, in which Journals, Conferences, Books, among other sources, the articles have been published. It was possible to identify the main sources of the publication in which this theme is being published and discussed. Table 1 shows the sources that have obtained the largest number of publications in each of the databases. 
TABLE I

MAJOR PUBLICATION SOURCES

\begin{tabular}{lclr}
\hline \hline \multicolumn{2}{c}{ ISI Web of Knowledge } & \multicolumn{2}{c}{ Scopus } \\
\hline \hline \multicolumn{1}{c}{ Source publication } & Qty & Source publication & Qty \\
\hline $\begin{array}{l}\text { Information and Software } \\
\text { Technology }\end{array}$ & 3 & $\begin{array}{l}\text { Lecture Notes in } \\
\text { Computer Science }\end{array}$ & 3 \\
\hline \hline
\end{tabular}

The journal Information and Software Technology is classified with 1,569 of Impact Factor (IF) by JCR (Journal Citation Reports) [28]. However, the Lecture Notes in Computer Science does not have IF by JCR [28].

The principal authors of the 65 papers were identified using a feature provided by the databases. Table 2 presents the author with the largest number of publications in the two studied databases.

TABLE II

MAIN AUTHORS AT ISI Web OF KNOWLEDGE AND SCOPUS DATABASES

\begin{tabular}{lrlc}
\hline \hline \multicolumn{2}{c}{ ISI Web of Knowledge } & \multicolumn{2}{c}{ Scopus } \\
\hline \hline \multicolumn{1}{c}{ Author } & Qty & \multicolumn{1}{c}{ Author } & Qty \\
\hline Book, Matthias & 2 & Farid, Weam M & 3 \\
Farid, Weam M & 2 & Mitropoulos, Frank J & 3 \\
Grapenthin, Simon & 2 & & \\
Gruhn, Volker & 2 & & \\
Huang, Philip M & 2 & & \\
Knuth, Andrew A & 2 & & \\
Mitropoulos, Frank J & 2 & & \\
Poggel, Steven & 2 & & \\
\hline \hline
\end{tabular}

The databases also provided a resource to identify in which countries the theme has being more discussed and published. According to [23], the evaluation of publications by country allows you to discover if the behavior of references is dependent on the internationality of the work and consider that authors of different nationalities may have different information and habits.

Therefore, as can be seen in Figure 3, the United States is the country that leads the number of publications at ISI Web of Knowledge database.

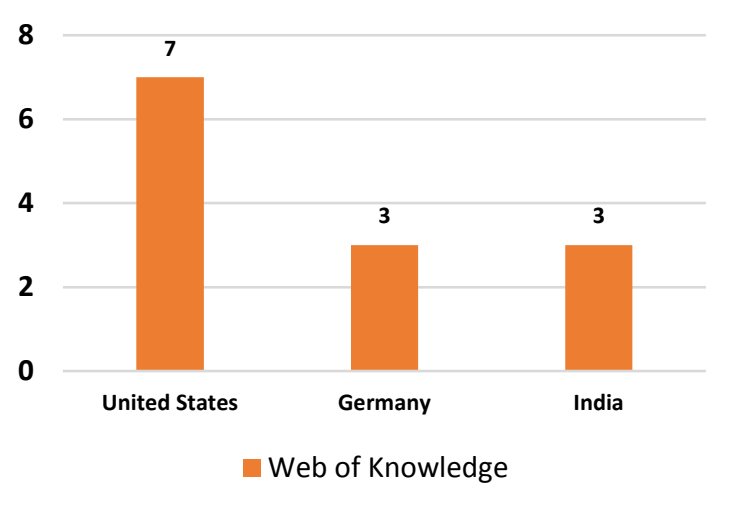

Fig. 4. Countries with higher number of articles published at ISI Web of Knowledge

Figure 4 presents the countries with the highest number of publications at Scopus database. The United States is the country with the highest number of publications.

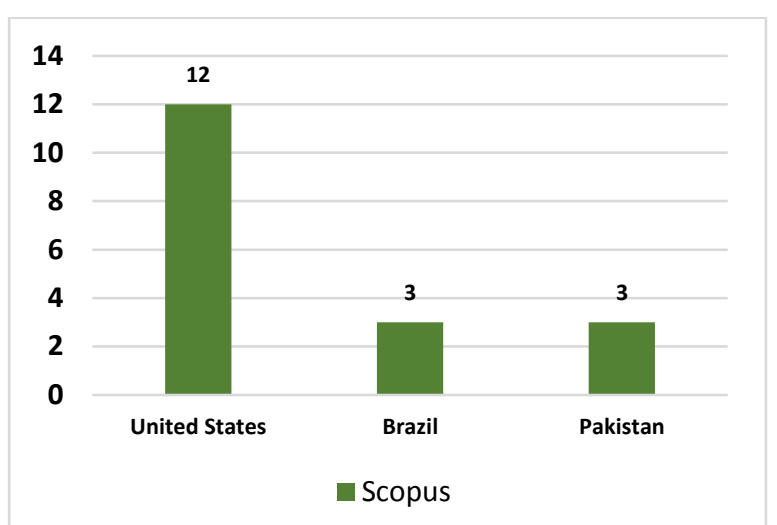

Fig. 5. Countries with higher number of articles published at Scopus

The last analysis performed using the IS Web of Knowledge and Scopus resources, was the construction of the citations map. The citation map is a tool used in order to connect the articles with its respective articles cited and the most cited article remains in the center of the map.

Based on the data in Figure 2, it was possible to identify the article with the highest number of citations at ISI Web of Knowledge database, which is: Risks and risk mitigation in global software development: A tertiary study, by the authors JM Verner, OP Brereton, BA Kitchenham, M Turner and M Niazi. This article was published in 2014 in the Information and software technology journal and received 22 citations at ISI Web of Knowledge.

The article with the highest number of citations in the Scopus database is: Risk identification and mitigation processes for using scrum in global software development: A conceptual framework, by the authors Emam Hossain, Muhammad Ali Babar, Hye-young Paik and June M. Verner, published in 2009 in the Asia-Pacific Software Engineering Conference. This paper received 19 citations at Scopus.

The citations map resource from CiteSpace ${ }^{\circledR}$ software allows to view and analyze trends and patterns in a research field or domain within a certain period of time [9]. The map was created in order to identify the most cited authors. Figure 5 shows the authors cited by at least 4 of the studies analyzed at ISI Web of Knowledge.

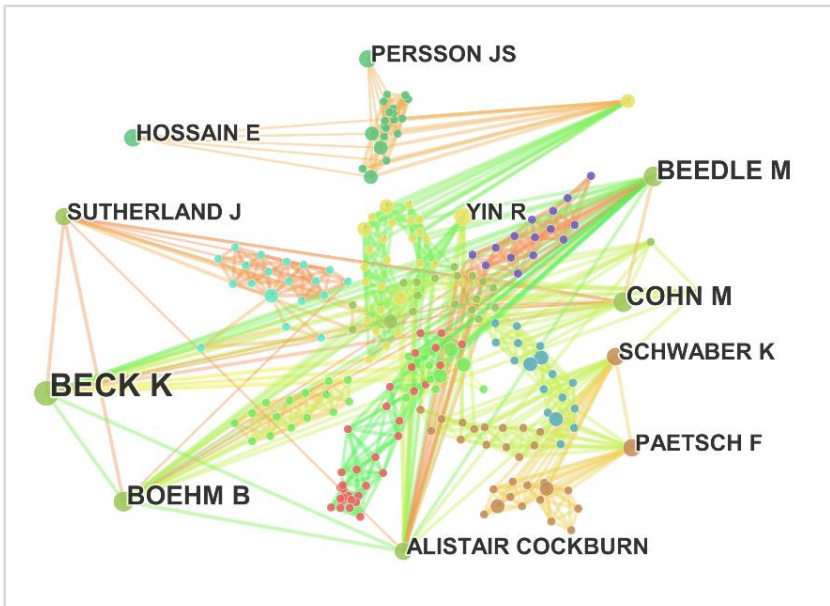

Fig. 6. Citation map of the articles from ISI Web of Knowledge 
Table 3 shows these same authors and the number of times they have been cited. It is observed that the author Kent Beck received the highest number of citations.

TABLE III

\begin{tabular}{lc}
\multicolumn{2}{c}{ MAIN AUTHORS AT ISI WEB OF KNOWLEDGE } \\
\hline \hline Authors & Qty \\
\hline \hline Beck K. & 5 \\
Beedle M. & 4 \\
Boehm B. & 4 \\
Cohn M. & 4 \\
Alistair Cockburn. & 3 \\
Schwaber K. & 3 \\
Paetsch F. & 3 \\
Yin R. & 3 \\
Sutherland J. & 3 \\
Hossain E. & 3 \\
Persson JS. & 3
\end{tabular}

The citation was also created for the Scopus. Figure 6 shows the authors cited by at least 5 of the studies analyzed from this database.

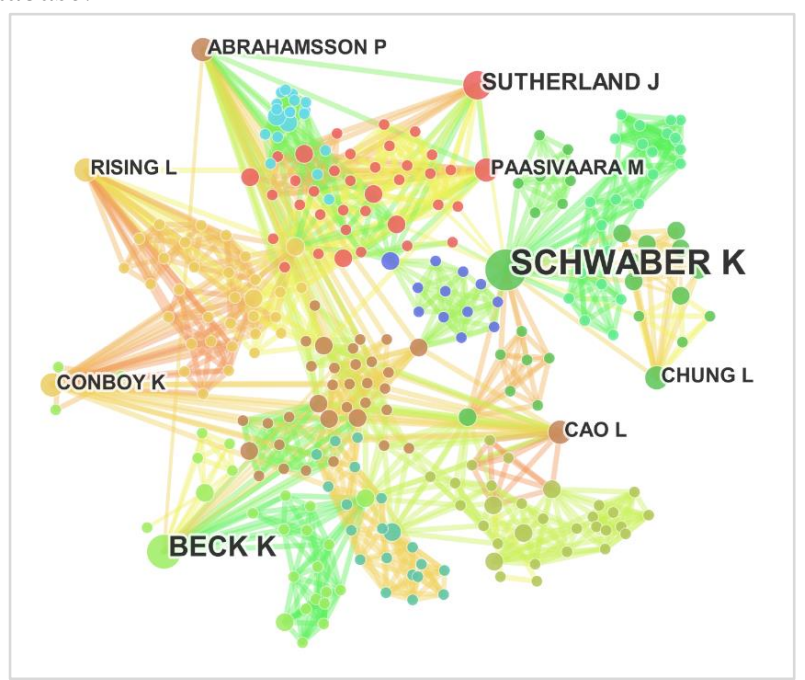

Fig. 7. Citation map of the articles from Scopus

Table 4 shows these same authors and the number of times they have been cited. It is observed that the author Ken Schwaber received the highest number of citations at Scopus.

TABLE IV

\begin{tabular}{lc}
\multicolumn{2}{c}{ MAIN AUTHORS AT SCOPUS } \\
\hline \hline \multicolumn{1}{c}{ Authors } & Qty \\
\hline \hline Schwaber K. & 3 \\
Beck K. & 6 \\
Sutherland J. & 3 \\
Abrahamsson P. & 2 \\
Chung L. & 2 \\
Cao L. & 2 \\
Rising L. & 2 \\
Conboy K. & 2 \\
Paasivaara M. & 2 \\
\hline \hline
\end{tabular}

It is important to emphasize that the authors Kent Beck and Ken Schwaber got an outstanding position in both analyzed databases.

The last analysis in this study includes the identification of the main keywords of the articles analyzed through the CiteSpace ${ }^{\circledR}$ software. For [26], keywords are the most important identifiers of articles and allow to identify which topics are the most discussed within a research area. The identification of the main keywords also improves the search strings of the bibliometric study.

Figure 6 presents the keywords that were mentioned by 2 or more articles analyzed at ISI Web of Knowledge. The term "Scrum" stands out in Figure 7 because it is the most mentioned.

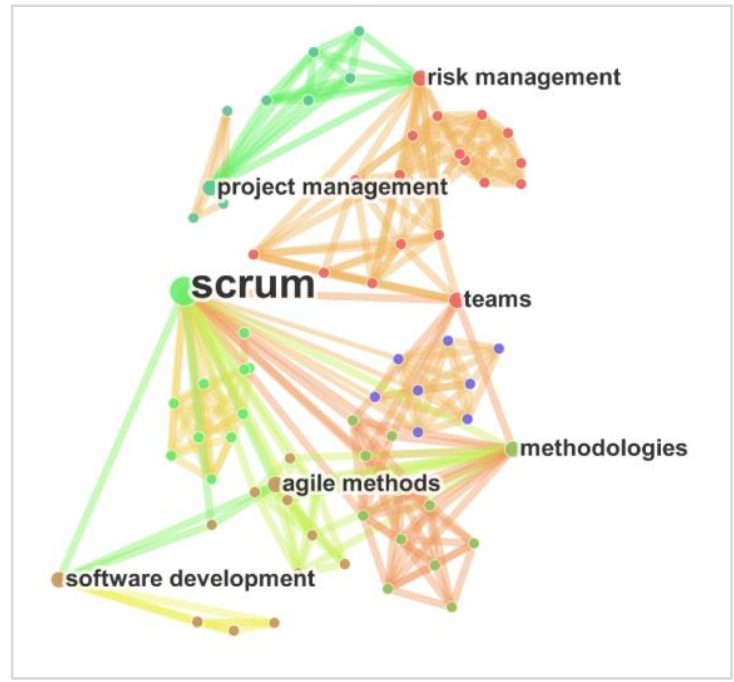

Fig. 8. Map of the main keywords cited by the articles from ISI Web of Knowledge

This analysis is important because allowed to find that other terms may be used in the search for articles related to this theme. For example, the terms "methodologies" and "agile methods" showed differences in their use.

Table 5 shows the keywords from Figure 7 and the number of times they were cited. It is observed that the term "Scrum" was the most cited.

TABLE V

MAIN KEYWORDS CITED BY THE ARTICLES FROM ISI WEB OF KNOWLEDGE

\begin{tabular}{lc}
\hline \hline \multicolumn{1}{c}{ Keywords } & Qty \\
\hline \hline Scrum & 5 \\
Agile Methods & 3 \\
Methodologies & 3 \\
Project Management & 3 \\
Software Development & 3 \\
Risk Management & 3 \\
Teams & 3 \\
\hline \hline
\end{tabular}

The citation map of the main keywords was also created for the Scopus. Figure 8 presents the keywords that were mentioned by 2 or more articles. The terms "Scrum" and "Project Management", stand out in Figure 8 because they are the most frequently cited among the keywords. 


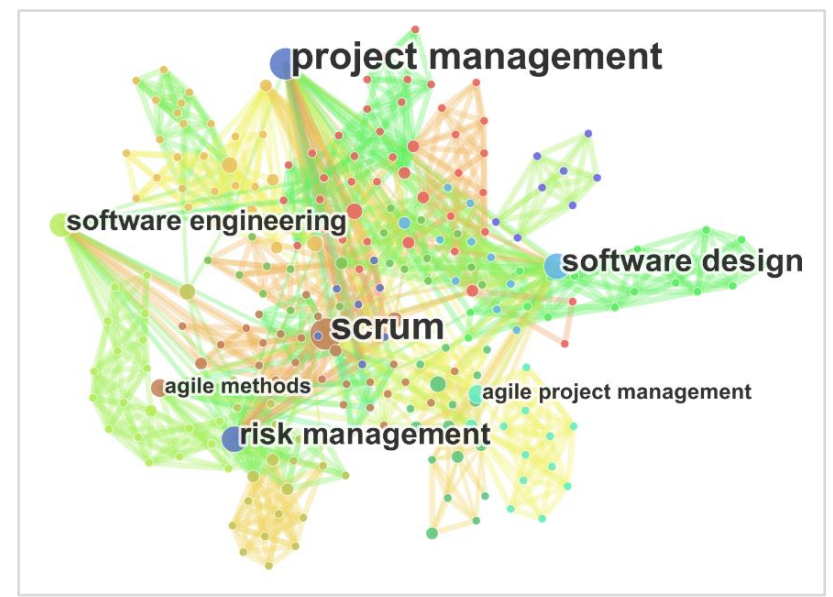

Fig. 9. Map of the main keywords cited by the articles from Scopus

Table 6 shows the main keywords with their respective number of citations.

TABLE VI

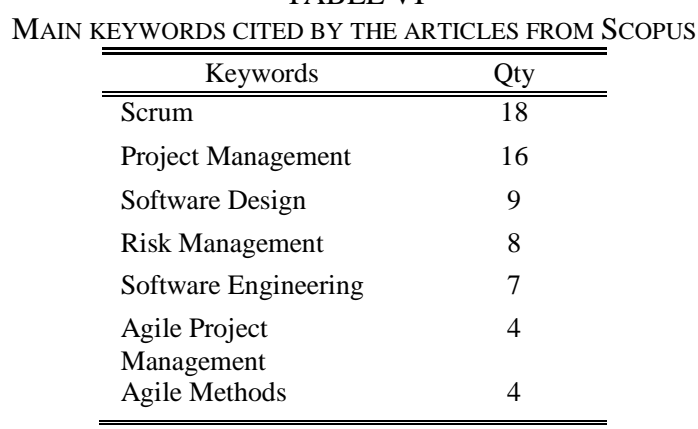

The terms "Scrum" and "Project Management" stand out on both studied databases, ISI Web of Knowledge and Scopus.

\section{CONCLUSION}

In this study, bibliometric approaches were used to quantitatively and qualitatively investigate the global research trends of risk management in Scrum projects during the period of 2007-2017. Initially, we conducted a survey using the two studied databases: ISI Web of Knowledge and Scopus. The number of articles found at ISI Web of Knowledge and Scopus were 23 and 42, respectively. The search was limited to publications between the years 2007 and 2017.

From the identified articles, the bibliometric study was performed using the resources of the ISI Web of Knowledge and Scopus. The analyzes for both databases were: analysis of publications and citations; identifying the major sources of publication, authors and countries; construction of citation maps. The citation maps were created with the support of the CiteSpace ${ }^{\circledR}$ software, enabling the identification of the main authors cited by the articles analyzed, besides the most common keywords. We observed that the author Ken Schwaber is the most cited in the 50 studies analyzed.

This study enables researchers to know the main features of the publications of Risk Management in Scrum Projects. The results indicate that the subject has a significant number of articles and an increase in the number of papers in the last 10 years. Furthermore, we observed an increase in the number of citations in the last 5 years. The United States is the country with the highest number of publications on this theme. The study also identified some sources of potential publications and queries that can support the state of the art, highlighting the Information and Software Technology journal and the Lecture Notes in Computer Science.

For future work, we suggest to carry out a research of impediment management as a technique to manage risks in Scrum projects. Despite of the importance of this subject, none of the articles identified focused on impediment management. Besides, the maps developed using ISI Web of Knowledge and Scopus databases, did not identified impediment as one of the most cited keywords.

\section{ACKNOWLEDGMENT}

The authors need to express their acknowledgments to three Brazilian research agencies: the CAPES Foundation, CNPq and FAPEMIG, and especially all interviewees and reviewers.

\section{REFERENCES}

[1] Abdullah Al Murad Chowdhury and Shamsul Arefeen. Software Risk Management: Importance and Practices. International Journal of Computer and Information Technology (IJCIT), v. 02, n. 01, 2011.

[2] Alan Moran. Agile Risk Management. SpringerBriefs in Computer Science, p. 33-60, 2014.

[3] C. A. Araujo. Bibliometria: evolução, história e questões atuais. Em Questão, Porto Alegre, v. 12, n. 1, p. 11-32, 2006.

[4] C. Chen. Searching for intellectual turning points: Progressive knowledge domain visualization. Proceedings of the National Academy of Sciences, p. 5303-5310, 2004.

[5] C. R. Woszezenki and A. L. Gonçalvez. Mineração de textos biomédicos: uma revisão bibliométrica. Perspectivas em Ciência da Informação, v. 18, n. 3, p. 24-44, 2013.

[6] C. William Ibbs and Young Hoon Kwak. Assessing Project management maturity. Project Management Journal, v. 31, n. 1, p. 32-43, 2000.

[7] Christopher R. Nelson, Gil Taran and Lucia de Lascurain Hinojosa. Explicit Risk Management in Agile Process. In: XP 2008, p. 190-201, 2008

[8] Eman Talal Alharbi and M. Rizwan Jameel Qureshi. Implementation of Risk Management with SCRUM to Achieve CMMI Requirements. I.J. Computer Network and Information Security, v. 11, p. 20-25, 2014.

[9] G. Liu, R. Jiang and Y. Jin. Sciatic nerve injury repair: A visualized analysis of research fronts and development trends. Neural Regeneration Research, v. 9, p. 1716-1722, 2014.

[10] Haneen Hijazi, Thair Khdour and Abdulsalam Alarabeyyat. A Review of Risk Management in Different Software Development Methodologies. International Journal of Computer Applications, v. 45, n. 7, p. 8-12, 2012.

[11] Ivaldir H. de Farias Junior, Ryan R. de Azevedo, Hermano P. de Moura and Dennis S. Martins da Silva. Elicitation of Communication Inherent Risks in Distributed Software Development. IEEE Seventh International Conference on Global Software Engineering Workshops, p. 37-42, 2012.

[12] J. Sun, M.H. Wang, Y.S. HO. A historical review and bibliometric analysis of research on estatuary pollution. Marine Pollution Bulletin, v. 64, n. 1, p. 13-21, 2012.

[13] Jaana Nyfjord and Mira Kajko Mattsson. Commonalities in Risk Management and Agile Process Models. Conference on Software Engineering Advances (ICSEA), 2007. 
[14] Javier Garzás and Mark C. Paulk. A case study of software process improvement with CMMI-DEV and Scrum in Spanish companies. Journal of Software: Evolution and Process, v. 25, e. 12, p. 1325-1333, 2013.

[15] Kenneth S. Rubin, Essential scrum: A practical guide to the most popular agile process, Addison-Wesley, 2012.

[16] Ken Schwaber and Jeff Sutherland. The Scrum Guide. Scrum.org, 2013.

[17] L. Bufrem and Y. Prates. O saber científico registrado e as práticas de mensuração da informação. Ciência da Informação, Brasília, v. 34, n. 2, p. 9-25, 2005.

[18] Lokman I. Meho and Kiduk Yang. Impact of data sources on citation counts and rankings of LIS faculty: Web of science versus scopus and google scholar. Journal of the American Society for Information Science and Technology, v. 58, n. 13, p. 2105-2125, 2007.

[19] Lutz Bornmann; Werner Marx; Hermann Schier, Erhard Rahm; Andreas Thor and Hans-Dieter Daniel. Convergent validity of bibliometric Google Scholar data in the field of chemistry Citation counts for papers that were accepted by Angewandte Chemie International Edition or rejected but published elsewhere, using Google Scholar, Science Citation Index, Scopus, and Chemical Abstracts. Journal of Informetrics, v. 3, n. 1, p. 27-35, 2009.

[20] M. das G. Targino and J. C. R. Garcia. Ciência brasileira na base de dados do Institute for Scientific Information (ISI). Ciência da Informação, Brasília, v. 29, n. 1, p. 103-117, jan/abr. 2000.

[21] M.J. Cobo, A.G. López-Herrera, E. Herrera-Viedma and F. Herrera. An approach for detecting, quantifying, and visualizing the evolution of a research field: A practical application to the fuzzy sets theory field. Journal of Informetrics, v. 5, n. 1, p. 146166, 2001.

[22] M.W.C. Gumpenberger and J. Gorraiz. Bibliometric practices and activities at the University of Vienna. Library Management, v. 33, n. 3, p. 174-183, 2012.

[23] Olle Persson, Wolfgang Glanzel and Rickard Danell. Inflationary bibliometric values: The role of scientific collaboration and the need for relative indicators in evaluative studies. Scientometrics, v. 60, n. 3, p. 421-432, 2004.

[24] Paula Vanessa Medeiros Vieira and Jacques Wainer. Correlações entre a contagem de citações de pesquisadores brasileiros, usando o Web of Science, Scopus e Scholar. Perspectivas em Ciência da Informação, v. 18, n. 3, p. 45-60, 2013.

[25] R. N. Machado. Análise cientométrica dos estudos bibliométricos publicados em periódicos da área de biblioteconomia e ciência da informação (1990-2005). Perspectivas em ciência da informação, v. 12, n. 3, p. 2-20, 2007.

[26] Saeed Samiee and Brian R. Chabowski. Knowledge structure in international marketing: a multi-method bibliometric analysis. Journal of the Academy of Marketing Science, v. 40, n. 2, p. 364 386, 2012.

[27] Terry Lima Ruas and Luciana Pereira. Como construir indicadores de Ciência, Tecnologia e Inovação usando Web of Science, Derwent World Patent Index, Bibexcel e Pajek? Perspectivas em Ciência da Informação, v. 19, n. 3, p. 52-81, 2014.

[28] Thomson-Reuters. Journal Citation Reports. Available at: http://about.jcr.incites.thomsonreuters.com/. Accessed on: February 26th 2015.

[29] Y. Okubo. Bibliometric indicators and analysis of research systems: methods and examples. Paris: OECD, 1997.

[30] The Standish Group. The CHAOS Manifesto. The Standish Group, 2013.

[31] Versionone INC. 8th Annual State of Agile Survey. VersionOne, Inc, 2014.

[32] PMI - Project Management Institute, Capítulo de São Paulo. Available at: http://www.pmisp.org.br. Acessed on: February 26th 2017.
[33] Thomas E. Murphy, Jim Duggan, David Norton, Brian Prentice, Daryl C. Plummer and Susan Landry. Predicts 2010: Agile and Cloud Impact Application Development Directions. Gartner Reaserch, 2009.

[34] B. de Wet and J.K. Visser. An evaluation of software project risk management in South Africa. South African Journal of Industrial Engineering, v. 24, n. 1, p. 14-28, 2013.

[35] SEI - Software Engineering Institute. CMMI - Capability Maturity Model Integration. Version 1.3, Pittsburgh, PA, Carnegie Mellon University, USA, 2010.

[36] Farlex. The free Dictionary. Available at: http://www.thefreedictionary.com/framework. Acessed on: February 26th 2017.

[37] Júlio Menezes, C.M.G. Gusmão and Hermano Moura. Defining Indicators for Risk Assessment in Software Development Projects. CLEI Electronic Journal, v. 16, n. 1, 2013.

[38] Ana Sofia C. Marçal, Bruno Celso C. de Freitas, Felipe S. Furtado Soares and Arnaldo D. Belchior. Mapping CMMI Project Management Process Areas to SCRUM Practices. Software Engineering Workshop, p. 13-22, 2007.

[39] Martin Tomanek and Jan Juricek. Project Risk Management Model Based on PRINCE2 and Scrum Frameworks, The International Journal of Software Engineering \& Applications (IJSEA), v. 6, n. 1, p. 81-88, 2015.

[40] R. N. Charette. Why software fails. IEEE Spectrum, v. 42, n. 9, p. 42-49, 2005.

[41] Sunil Kumar Khatri, Khushboo Bahri, Prashant Johri. Best Practices for Managing Risk in Adaptive Agile Process. International Conference on Reliability, Infocom Technologies and Optimization (ICRITO), p. 1-5, 2014.

[42] Victor Szalvay. Glossary of Scrum Terms. Available at: https://www.scrumalliance.org/community/articles/2007/march/gl ossary-of-scrum-terms\#1126. Acessed on: February 26th 2017.

[43] C.R. Jakobsen and K.A. Johnson. Mature Agile with a Twist of CMMI. Agile '08 Conference, 2008.

[44] Viljan Mahnic. Teaching Scrum through Team-Project Work: Students' Perceptions and Teacher's Observations. International Journal of Engineering Education, v. 26, n. 1, p. 96-110, 2010.

[45] T. Raz, A.J. Shenhar and D. Dvir. Risk management, project success, and technological uncertainty. R \& D Management. v. 32, n. 2, p.101-109, 2002 .

[46] Satya Prasad Ravi, B. Reddaiah, Lakshmi Sridhar Movva and Rajasekhar Kilaparthi. A Critical review and empirical study on success of risk management activity with respect to Scrum. Engineering Science and Technology: An International Journal (ESTIJ), v. 2, n. 3, p. 467-473, 2012.

[47] Wallace, L., Keil, M., Rai, A. How Software Project Risks Affect Project Performance: an Investigation of the Dimensions of Risk and an Exploratory Model. Decision Sciences, 35 (2), 289-321, 2004.

[48] Michele Gannon. "An Agile Implementation of SeRUM." (2013).

[49] S-J. Huang and W-M Han. Exploring the relationship between software project duration and risk exposure: A cluster analysis. Information and Management, 45 (3), 175-182, 2008.

[50] Tomohiro Hayata and Jianchao Han. A hybrid model for IT project with Scrum. IEEE International Conference on Service Operations, Logistics, and Informatics (SOLI), pp. 285-290, 2011.

[51] B. Barton. All-Out Organizational Scrum as an Innovation Value Chain. The 42nd Hawaii International Conference on System Sciences, Waikoloa, 2009.

[52] Ken Power. Impediment Impact Diagrams: Understanding the Impact of Impediments in Agile Teams and Organizations. Agile Conference. Proceedings of a meeting held 28 July - 1 August 2014, Orlando, Florida, 2014. 


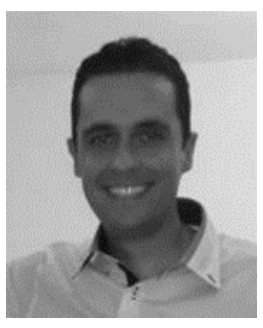

Breno G. Tavares graduated in Computer Science (UNIFENAS), graduated in Business Administration (UFLA), 2011, MBA in Computing (UFMG), 2004, MBA in Software Process Improvement (UFLA), 2006, MBA in Production Engineering (IETEC), 2010, Master Degree in Production Engineering (UNIFEI), 2015. He is currently pursuing the Ph.D. degree in production engineering at Federal University of Itajubá (UNIFEI). Communications and Information Technology Manager at Nacional Institute of Telecomunications (INATEL), Santa Rita do Sapucaí, Brazil. He possess the PMP - Project Management Professional certification from PMI, PMI-RMP Risk Management Professional certification from PMI and PSM - Professional Scrum Master from Scrum.org.

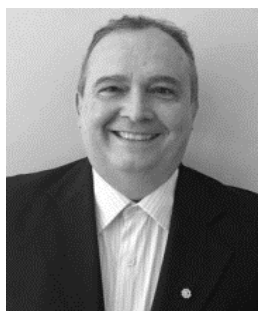

Carlos Eduardo S. da Silva graduated in Economy (1989 - FACESM), Mechanical Engineer (1990 - UNIFEI), MBA in Quality and Productivity (1994 - UNIFEI), Master Degree in Industrial Engineering (1996 - UNIFEI), Doctor in Industrial Engineering (2001 UFSC), post-doctorate at University of Texas (2009). Professor at Federal University of Itajubá (UNIFEI) - Undergraduate and Postgraduate. Research interests: project management and product development. Member of the FAPEMIG Committee (2010-2012), CAPES (2010 - 2012). Scientific Director of the Brazilian Association of Industrial Engineering - ABEPRO (2010-2011). Currently is ProRector of Post-Graduate Studies and Research at UNIFEI (2013 current).

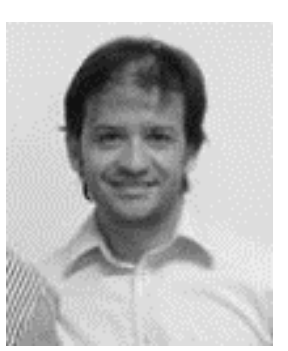

Adler Diniz de Souza graduated in Science Computer by the Federal University of Lavras (UFLA), 2004, Project Management Professional (PMP), 2005, MBA in Software Process Improvement (UFLA), 2005, Master in System Engineering and Computer by the COPPE / PESC / UFRJ, 2008, PhD in System Engineering and Computer by the COPPE / PESC / UFRJ, 2014. Professor Federal University of Itajubá (UNIFEI) Undergraduate and Postgraduate. Research interests: Project Management, Software Process Improvement, Portfolio Management, Earned Value Management (EVM). 